\title{
PERANCANGAN TATA CAHAYA PADA INTERIOR RUMAH TINGGAL
}

\author{
Dila Hendrassukma \\ Interior Design Department, School of Design, BINUS University \\ Jln. K.H. Syahdan No. 9, Palmerah, Jakarta Barat 11480 \\ justdila@gmail.com
}

\begin{abstract}
Homestay is a place where each individual coming back after doing her/his routine and non-routine daily activities. A good residential interior design would enhance the quality of life of its inhabitants. The majority of Indonesian population, Jakarta in particular, has been aware of the importance of designing their home interior properly. However, home interior lighting, which is key to successful design of an interior space, is often under-emphasized. Research tried to collect lighting techniques often used in residential interiors. The result is a brief explanation and easy to apply regarding the types of information that can be used to illuminate any activity on the interior of the residence. Qualitative method by literature study is used in the making of this research.
\end{abstract}

Keywords: home interior, home lighting design, home design

\begin{abstract}
ABSTRAK
Rumah tinggal merupakan tempat setiap individu kembali setelah melakukan berbagai aktivitas rutin dan tidak rutin sehari-hari. Perancangan interior rumah tinggal yang baik akan mendukung kualitas hidup penghuninya. Mayoritas penduduk Indonesia, Jakarta pada khususnya, telah sadar pentingnya merancang interior rumah tinggal mereka dengan baik. Namun tata cahaya interior rumah, yang merupakan kunci keberhasilan desain sebuah interior ruang, sering kali dinomorduakan. Penelitian mengumpulkan teknik-teknik pencahayaan yang sering kali dipakai di interior rumah tinggal. Hasilnya merupakan penjelasan singkat dan mudah untuk diaplikasikan mengenai jenis-jenis penerangan yang dapat digunakan untuk menerangi setiap aktivitas yang terdapat pada interior rumah tinggal. Metode yang dipakai dalam penelitian adalah kualitatif studi literatur.
\end{abstract}

Kata kunci: interior rumah tinggal, desain pencahayaan rumah tinggal, desain rumah tinggal 


\section{PENDAHULUAN}

Penerangan ruang merupakan hal yang tidak kalah penting dibandingkan dengan elemen interior ruang seperti warna, material, dan detail furnitur. Dapat dikatakan seorang desainer interior akan sia-sia pekerjaan, waktu, dan dana yang telah dikeluarkannya jika tidak memikirkan penerangan yang terdapat pada interior ruang rancangannya. Hal tersebut pun berlaku di kala seorang desainer telah merancang sebuah ruangan dengan menggunakan material terbaik, warna terkini, maupun detail elemen desain yang tiada tandingannya. Cahaya dan efek yang dihasilkan dalam sebuah interior ruang merupakan kunci untuk menikmati dan keberhasilan fungsi dari sebuah ruang. Cahaya dan bayangan yang diciptakan akan menerangi bentuk dan memperjelas tekstur ruang. Cahaya juga menjadikan warna-warna ruang dapat terlihat oleh mata. Jika sebuah penerangan interior ruang dirancang dengan baik, desainer interior juga dapat menciptakan sebuah atmosfer ruang yang sesuai dengan fungsi ruangan tersebut.

\section{METODE}

Metode kualitatif digunakan dalam penelitian ini dengan observasi dan studi literatur. Penulis melakukan studi literatur terhadap tulisan-tulisan mengenai pencahayaan interior arsitektur rumah tinggal serta mengobservasi hunian di sekelilingnya. Setelah melakukan studi literatur dan observasi lapangan, penulis menganalisis data tersebut dan hubungannya dengan fungsi ruangan. Pada akhirnya penulis memperoleh simpulan mengenai pencahayaan yang tepat untuk tiap-tiap ruang dalam sebuah rumah tinggal.

\section{HASIL DAN PEMBAHASAN}

Desain dari sebuah interior rumah tinggal merupakan cerminan individu yang menempatinya. Penghuni sebuah rumah tinggal, khususnya di Indonesia, sering kali terdiri dari satu individu. Hal tersebut membuat perancangan interior rumah tinggal harus dengan penuh pertimbangan dan perhitungan karena aktivitas yang terjadi di dalamnya cukup beragam. Ruang-ruang di dalamnya pun dirancang sesuai dengan aktivitas yang diperuntukkan. Penataan cahaya ruang merupakan sentuhan akhir dan merupakan yang terpenting untuk keberhasilan ruang-ruang tersebut sehingga penghuni dapat memaksimalkan aktivitas mereka.

\section{Foyer}

Pada zaman sekarang telah banyak rumah di Indonesia yang mempunyai foyer di dalamnya. Foyer merupakan ruang terdepan di sebuah rumah. Pada dasarnya foyer adalah area transisi antara pintu masuk dan koridor rumah yang menuju ruang-ruang lain. Foyer juga dapat disebut sebagai sampul kedua sebuah rumah, setelah façade rumah tersebut, karena tampilan foyer dapat mencerminkan lebih detail mengenai pemilik rumah. Biasanya pada foyer terdapat pajangan atau hiasan-hiasan ruang koleksi dari pemilik rumah. Aktivitas yang terjadi di area foyer umumnya berlangsung singkat. Penghuni maupun tamu hanya melewati area tersebut untuk menuju ruang khusus yang lebih dapat memfasilitasi kegiatan. Namun bukan berarti foyer tidak harus diperhatikan perancangan desainnya.

Karena sifatnya sebagai area transisi, penerangan pada area foyer dapat lebih ditekankan pada penerangan dekoratif, seperti lampu meja pada meja console atau lampu sorot di atas lukisan pada 
dinding (Akmal, 2006). Pencahayaan dekoratif pada area foyer adalah untuk mencapai sebuah atmosfer yang mengundang tamu untuk masuk lebih jauh ke rumah, jika diinginkan oleh pemilik. Atmosfer resmi dapat diraih dengan menggunakan intensitas cahaya yang lebih terang. Sedangkan untuk atmosfer yang lebih akrab dapat diciptakan dari intensitas cahaya yang lebih lembut, biasanya menggunakan lampu berwarna kuning. Walaupun demikian, jenis penerangan general lighting tetap dibutuhkan karena pengguna ruang harus dapat melihat arah yang mereka tuju demi faktor keamanan. General lighting dapat dihasilkan dari lampu gantung yang diposisikan di tengah area foyer.

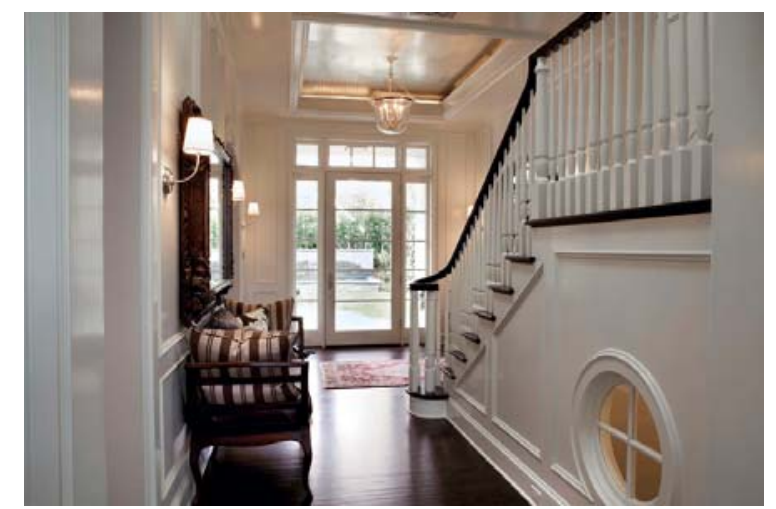

Gambar 1 Foyer ini diterangi oleh lampu gantung dan lampu dinding (www.cococozy.com)

\section{Ruang Tamu}

Ruang tamu merupakan sebuah ruang tempat penghuni atau pemilik rumah menerima tamu yang datang. Pada saat ini keberadaan ruang tamu telah banyak dihilangkan dari arsitektur rumah modern di Indonesia. Namun masih banyak pula rumah yang menginginkan keberadaan ruangan ini mengingat budaya masyarakat Indonesia yang menjunjung tinggi nilai kekeluargaan. Aktivitas yang terdapat pada ruang tamu pada umumnya mencakup duduk dan berbincang-bincang. Aktivitas ini dapat bersifat formal maupun santai, tergantung dari kedekatan penghuni dengan tamu yang datang.

Ruang tamu disarankan mempunyai general lighting yang dapat menyinari keseluruhan ruang. General lighting dapat berupa beberapa titik downlight pada plafon, sebuah chandelier atau lampu gantung, atau indirect lighting yang disembunyikan di balik permukaan plafon. Pencahayaan dapat digabungkan dengan decorative lighting, berupa lampu meja atau lampu sorot yang menghiasi pajangan dinding, yang dapat membantu menciptakan atmosfer keakraban sehingga menimbulkan kenyamanan bagi tamu di rumah tersebut.

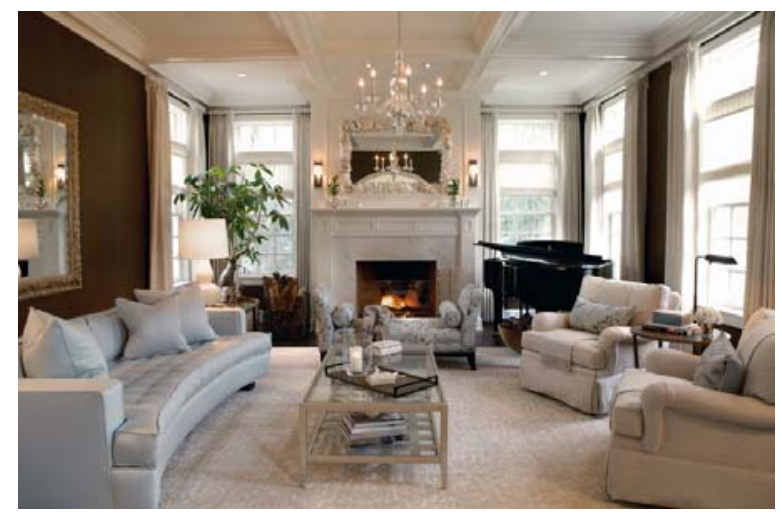

Gambar 2 Contoh penerangan pada ruang tamu (www.cococozy.com) 


\section{Ruang Keluarga}

Ruang keluarga dapat disebut sebagai pusat kegiatan di dalam rumah. Pada umumnya di ruangan ini seluruh anggota keluarga berkumpul untuk melakukan berbagai aktivitas. Terdapat di dalamnya adalah aktivitas menonton televisi, membaca, menjahit, ataupun sekadar berbincangbincang. Perancangan interior ruang keluarga sangatlah penting untuk mendukung kebersamaan dan kenyamanan dalam mengerjakan aktivitas yang ada.

Jenis pencahayaan yang digunakan pada ruang keluarga sebaiknya adalah general lighting berupa downlight untuk memfasilitasi keberagaman aktivitas yang terjadi di ruangan tersebut. Ada baiknya jika downlight diposisikan di beberapa titik sehingga dapat menyinari ruang secara merata. Untuk menciptakan suasana nyaman dan hangat dapat digunakan lampu berwarna kuning dengan intensitas sedang. Untuk mempercantik ruangan dapat ditambahkan spot light untuk menerangi hiasan dinding. Penempatan lampu meja pada meja sudut dapat mengundang pengguna ruang untuk duduk santai pada kursi di sebelah meja tersebut. Standing lamp dapat disertakan di sebuah sudut di antara sofa untuk membantu penerangan aktivitas membaca.

\section{Ruang Makan}

Selain ruang keluarga, ruang makan adalah ruangan lain dalam rumah tinggal yang merupakan tempat berkumpul penghuni rumah. Ruang makan tidak hanya berfungsi untuk menampung aktivitas makan, aktivitas mengobrol santai pun dapat terjadi di meja makan.

Penerangan ruang makan yang baik adalah cahaya yang dapat menerangi makanan di atas meja makan dan dapat membantu membuat makanan tampak lebih menarik. General lighting dibutuhkan untuk menerangi keseluruhan ruangan, dapat berupa downlight ataupun indirect lighting. Jika penerangan ruang menggunakan indirect lighting, dapat ditambahkan task light berupa lampu gantung yang dipasang di atas meja makan dengan jarak $60 \mathrm{~cm}$ dari permukaan meja makan. Jarak tersebut dapat menerangi makanan secara optimal namun tidak menyilaukan mata.

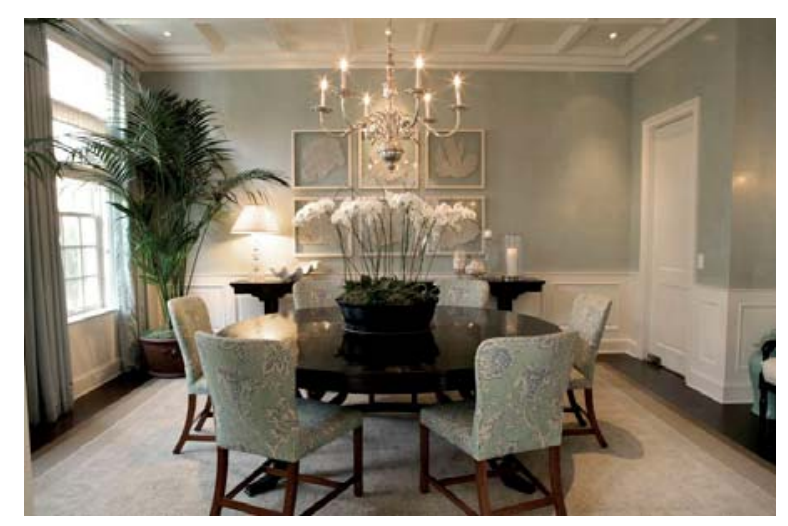

Gambar 4 Contoh desain pencahayaan pada ruang makan (www.cococozy.com)

\section{Dapur}

Sampai beberapa waktu lalu, desain dapur sebuah rumah tinggal bukan merupakan hal yang penting dikarenakan dapur terletak di bagian belakang rumah. Namun seiring dengan berkurangnya lahan untuk tempat tinggal, dapur sering kali ditempatkan dalam satu zona dengan ruang makan, dan terkadang ruang keluarga. Hal tersebut mengakibatkan dapur harus dirancang sedemikian rupa agar 
memiliki tampilan yang tidak kalah baik dan menariknya dengan area lain yang berdampingan dengannya.

Aktivitas yang terjadi di dapur mencakup menyiapkan dan mengolah makanan. Untuk dapur yang menyatu dengan ruang makan, dapur juga termasuk ruang perjamuan makan. Tata cahaya yang baik dapat menjadikan dapur tempat yang aman, higienis, dan nyaman untuk melakukan aktivitas di dalamnya. General lighting dibutuhkan untuk menerangi ruang dapur. Warna cahaya yang baik adalah yang paling mendekati daylight, sehingga pengguna akan dengan mudah mengetahui jika makanan yang dimasak sudah matang atau belum. Downlight dengan pencahayaan yang merata merupakan general lighting yang baik untuk dapur. Sebagai tambahan, task light berupa strip light ataupun lampu fluorescent dapat dipasang di tepi bawah kabinet agar dapat menerangi secara khusus aktivitas yang terjadi di atas meja dapur. Task light bergunan untuk menghindari terjadinya kecelakaan pada saat pengolahan makanan.

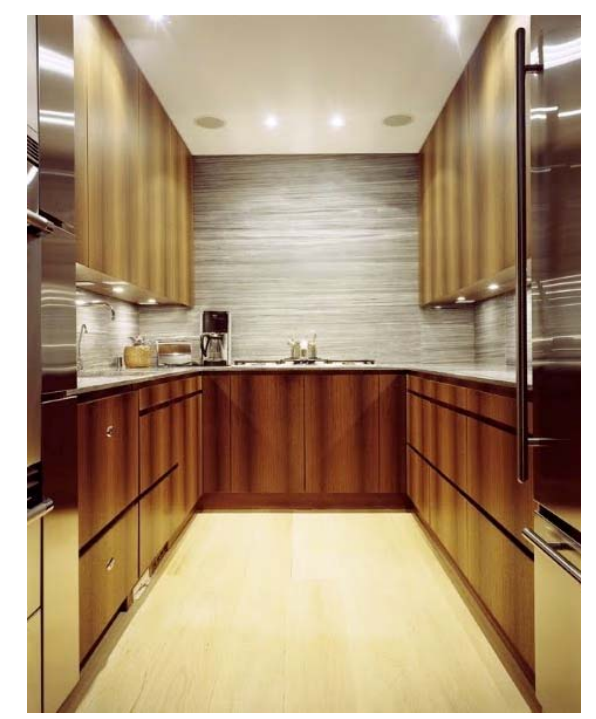

Gambar 5 Dapur yang diterangi oleh general lighting berupa titik-titik downlight pada plafon, dan task lighting berupa titik-titik halogen pada bawah kabinet

(www.yabupushelberg.com)

\section{Ruang Tidur}

Fungsi utama ruang tidur merupakan tempat untuk beristirahat. Maka pencahayaan pada ruang tidur haruslah dirancang untuk sebuah kenyamanan agar penggunanya dapat beristirahat dengan baik. Indirect lighting yang berasal dari balik tepi pinggiran plafon sangatlah sesuai diaplikasikan pada ruang tidur. Cahaya yang tidak langsung dengan intensitas rendah dapat membuat atmosfer ruangan lebih santai.

Untuk aktivitas lain seperti membaca atau berganti pakaian dapat menggunakan penerangan tambahan pada area masing-masing. Lampu baca dapat dipasang pada dinding di sebelah tempat tidur, begitu pula penempatan lampu meja pada bedside table. Masing-masing dari lampu itu dapat diberi dimmer agar dapat diatur intensitas cahayanya dan berfungsi sebagai lampu tidur. Sedangkan untuk aktivitas berganti pakaian dapat menggunakan downlight yang ditempatkan pada plafon di depan lemari. 


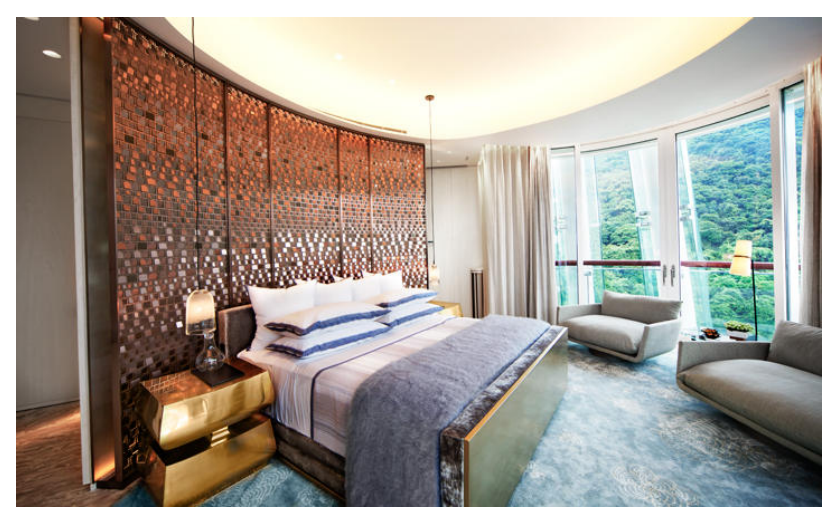

Gambar 6 Indirect lighting pada plafon merupakan general lighting pada ruang tidur ini. Lampu gantung pada kanan dan kiri tempat tidur merupakan task light yang dapat difungsikan sebagai lampu baca.

(www.wallpaper.com)

\section{Kamar Mandi}

Penerangan untuk kamar mandi diusahakan berasal dari sinar matahari yang masuk ke kamar mandi. Sinar matahari tidak hanya menerangi ruang, panas yang dibawa oleh sinar tersebut dapat mengurangi kelembaban pada kamar mandi. Namun pada waktu kamar mandi membutuhkan penerangan tambahan, misalnya pada malam hari, maka perlu diperhatikan aktivitas apa saja yang terjadi di kamar mandi.

Untuk aktivitas seperti sikat gigi, bercukur, dan berdandan yang biasanya bertempatan pada area wastafel, ruangan ini membutuhkan task lighting berupa downlight. Downlight dapat diposisikan tepat diatas meja wastafel. Aktivitas seperti mandi dan berendam termasuk aktivitas relaksasi, yang di sana pengguna membutuhkan atmosfer yang nyaman pada kamar mandi. Hal ini dapat diraih dengan menggunakan accent lighting berupa wall washer dengan lampu berwarna kuning yang menimbulkan kesan hangat. Namun perlu diperhatikan bahwa intensitas cahaya haruslah dapat menerangi setiap langkah pengguna di dalam kamar mandi demi menghindari terjadinya kecelakaan.

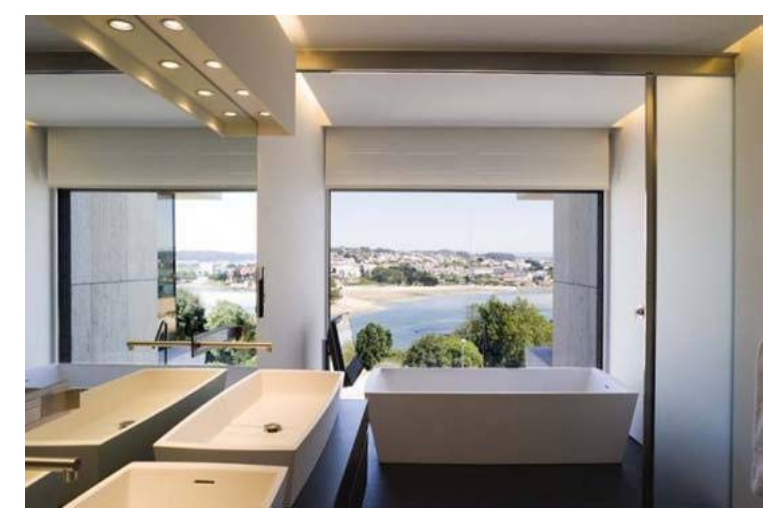

Gambar 7 Contoh desain pencahayaan pada kamar mandi (www.a-cero.com)

\section{SIMPULAN}

Rumah tinggal merupakan tempat yang terdapat berbagai macam aktivitas di dalamnya. Sebuah rumah tinggal yang baik bagi penghuninya adalah yang dapat memfasilitasi aktivitas 
penghuninya selama berada di dalam rumah. Perencanaan interior, termasuk perancangan tata cahaya, dapat membantu mewujudkan hal tersebut. Pencahayaan merupakan salah satu elemen desain interior yang terpenting. Tanpa perencanaan pencahayaan yang baik sebuah desain interior ruang tidak akan terlihat maksimal keindahannya. Selanjutnya, tanpa pencahayaan yang baik risiko kecelakaan kerja di dapur ataupun di kamar mandi dapat meningkat. Tata cahaya interior ruang secara tidak langsung juga dapat meningkatkan kesehatan pengguna ruang tersebut. Hal ini contohnya adalah perlunya intensitas cahaya yang tepat pada ruang tidur agar penghuni dapat beristirahat dengan kualitas maksimal; posisi lampu kerja atau task light pada spot tempat penghuni melakukan aktivitas membaca adalah contoh lainnya. Dengan adanya penulisan ini diharapkan masyarakat mulai menyadari pentingnya pencahayaan pada rumah hunian mereka.

\section{DAFTAR PUSTAKA}

Akmal, I. (2006). Lighting. Jakarta: Gramedia Pustaka Utama.

BBC. (2007, Oct). Homes. Diakses $26 \quad$ Agustus 2013 dari http://www.bbc.co.uk/homes/design/lighting_livingroom.shtml

Coles, J., \& House, N. (2007). The Fundamentals of Interior Architecture. Switzerland: Ava.

Indebleu. (2012, 12 Sept). Creative Ways in Designing Contemporary Entryway Lighting. Diakses 29 Agustus 2013 dari http://www.indebleu.net/creative-ways-in-designingcontemporary-entryway-lighting 